\title{
Auditory middle latency response in children with learning difficulties
}

\author{
Ana Claudia Figueiredo Frizzo', Myriam Lima Issac², Angela Cristina Pontes-Fernandes ${ }^{3}$, Pedro de Lemos Menezes ${ }^{4}$, \\ Carolina Araújo Rodrigues Funayama 5 .
}

1) PHD in Nueroscience, Medicine School of Ribeirão Preto - USP. Professor of the Department of Speech Pathology, Faculty of Sciences of the Universidade Estadual Paulista - FFC / UNESP, Marilia/SP - Brazil.

2) PHD in Medicine Pediatric Area, Medicine School of Ribeirão Preto - USP. Professor of the Department of Ophtalmology, Otolaryngology, Head Neck, Medicine School of Ribeirão Preto - USP, Ribeirão Preto/SP - Brazil.

3) PHD in Psichology, São Paulo University - USP. Hospital Psicologist oh the Medicine School Hospital of Ribeirão Preto - USP, Ribeirão Preto/SP - Brasil

4) PHD in Applied Physics in Medicine and Biology, São Paulo University-USP. Professor oh the Departament Speech Pathology of Alagoas State University Health Sciences - UNCISAL.

5) PHD and Full Professor in Child Neurology, Medicine School of Ribeirão Preto - USP. Professor of the Department of Neurology, Medicine School of Ribeirão Preto - USP, Ribeirão Preto/SP - Brazil.

Institution: Faculdade de Medicina de Ribeirão Preto - USP Faculdade de Filosofia e Ciências - FFC - UNESP. Marília / SP - Brazil.

Mailing address: Departamento de Fonoaudiologia Faculdade de Filosofia e Ciências Universidade Paulista - UNESP - Campus Marília - Avenida Hygino Muzzi Filho, 737 - Marília / SP - Brazil - Zip code: 17525-900.

Article received in November 16, 2011. Article approved in March 6, 2012.

\section{SUMMARY}

Introduction: This is an objective laboratory assessment of the central auditory systems of children with learning disabilities. Aim: To examine and determine the properties of the components of the Auditory Middle Latency Response in a sample of children with learning disabilities.

Methods: This was a prospective, cross-sectional cohort study with quantitative, descriptive, and exploratory outcomes. We included 50 children aged 8-13 years of both genders with and without learning disorders. Those with disorders of known organic, environmental, or genetic causes were excluded.

Results and Conclusions: The $\mathrm{Na}, \mathrm{Pa}$, and $\mathrm{Nb}$ waves were identified in all subjects. The ranges of the latency component values were as follows: $\mathrm{Na}=9.8-32.3 \mathrm{~ms}, \mathrm{~Pa}=19.0-51.4 \mathrm{~ms}, \mathrm{Nb}=30.0-64.3 \mathrm{~ms}$ (learning disorders group) and $\mathrm{Na}=13.2-29.6 \mathrm{~ms}$, $\mathrm{Pa}=21.8-42.8 \mathrm{~ms}, \mathrm{Nb}=28.4-65.8 \mathrm{~ms}$ (healthy group). The values of the $\mathrm{Na}-\mathrm{Pa}$ amplitude ranged from $0.3 \mathrm{to} 6.8 \mathrm{iV}$ (learning disorders group) or $0.2-3.6 \mathrm{iV}$ (learning disorders group). Upon analysis, the functional characteristics of the groups were distinct: the left hemisphere Nb latency was longer in the study group than in the control group. Peculiarities of the electrophysiological measures were observed in the children with learning disorders. This study has provided information on the Auditory Middle Latency Response and can serve as a reference for other clinical and experimental studies in children with these disorders. Keywords: evoked potentials, auditory, evoked potentials, learning.

\section{INTRODUCTION}

School failure stands out among the various human development indices as an important focus of political attention (1).

Studies of reading and writing have shown real progress in recent decades, especially in students with functional cerebral alterations (2). However, adverse social factors account for the majority of cases of school failure worldwide (2).

Given this context, it is necessary to find an objective laboratory-based method of assessing children with learning difficulties.

The Auditory Middle Latency Response (AMLR) has been the focus of research on patients with changes in language and learning $(3,4)$. The AMLR assists in verifying the integrity of the auditory pathways $(5,6)$. The acquisition of reading and writing using the alphabetic system involves the incorporation of acoustic elements of spoken language that are then translated into graphic symbols. The proper function of the afferent auditory pathway is crucial to efficient acoustic and phonological comprehension and enables the understanding and appropriate expression of the written code (7).

AMLRs are evoked bioelectrical responses that occur after a sound stimulus and consist of a series of waves ranging between 10 and $80 \mathrm{~ms}$ (8). The wave components that are most frequently considered, as they are the largest in amplitude and the most consistent, are $\mathrm{Na}, \mathrm{Pa}$, and $\mathrm{Nb}$ (2). The integrated study of central auditory nervous system function requires the use of at least 2 active electrodes (+) in order to compare the ipsilateral and contralateral sides. In addition, the electrodes must be placed over each brain hemisphere (left and right) in the regions of the left and right temporal lobes (T3, T4) and 
temporoparietal junctions (C3/C5, C4/C6) to optimize the sensitivity for purposes of neurodiagnosis research and facilitate the observation of the Middle Latency Response (6).

Audiology researchers have measured the AMLR in children with learning disorders and observed that the latency of the Na wave is longer and the amplitude of the $\mathrm{Nb}$ wave lower $(3,4)$.

This study aimed to compare the findings related to measures of AMLR between 2 groups, one without (control group) and another with (study group) school learning difficulties focused mainly on reading and writing.

\section{Method}

This was a prospective cross-sectional, quantitative, descriptive, and non-experimental study.

The project was approved by the Ethics Committee of the USP-HCFMRP, Case \# 118/2007.

The study participants were 25 children with learning difficulties aged between 8 and 14 years selected by convenience from the specialized ambulatory clinic for learning problems and the Division of Speech Pathology at Hospital das Clínicas, Medical School of Ribeirão Preto USP.

The control group consisted of an equal number of children of the same age with records of good school performance with no complaints and without family history of school difficulties.

Children were included only when a medical evaluation found no clinical evidence of any organic, socioenvironmental, or dysmorphic genetic disorder cause of their learning disabilities.

Children with conductive hearing loss, medication use, or a diagnosis of attention deficit disorder and hyperactivity with either hyperactive or mixed as the predominant form were excluded from the study.

The subjects in both groups underwent neurological and visual evaluation, measurement of auditory acuity, and recording of the AMLR. The experimental group also underwent psychological evaluations and testing of their executive functions (10) and intelligence levels (11) to assist in the diagnosis of their learning disorders.

All children in the study group showed significant academic impairment even when provided with academic enhancement activities. The following evaluation results were considered for analysis: the discrepancy between verbal IQ, performance on the psychological assessment $(9,10)$, abnormalities in memory, reading, and writing, oral reading of isolated words, writing dictated words, use of pseudowords (11), disorders of speech and writing, recognition of phonemes, syllables, rhyme, and alliteration in tests of phonological awareness (12), and significant abnormalities in syntactic and semantic language skills (13) and in otherareas of learning such as mathematical reasoning (14).

To record the AMLR, electrodes were placed at C3 and $\mathrm{C} 4$ (left and right hemispheres) with reference electrodes at A1 and A2 (left and right ears) and the ground electrode at Fz (forehead), in accordance with International Standard 10-2015, and matched with right and left side ipsilateral (R ipsi and L ipsi) and contralateral (R Contra and L Contra) electrodes. The stimulus consisted of monaural rarefied filtered clicks at $80 \mathrm{~dB} \mathrm{HL}$, with a presentation rate of 11 stimuli/second, analysis time (window) of $100 \mathrm{~ms}$, acoustic filter of 10 to $100 \mathrm{~Hz}$, and sensitivity of $75 \mu \mathrm{V}$, and the wave latencies of $\mathrm{Na}$ ( $\mathrm{Na}$ Lat), $\mathrm{Pa}$ (Pa Lat), and $\mathrm{Nb}$ ( $\mathrm{Nb}$ Lat) and the inter-wave amplitude of $\mathrm{Na}$-Pa were examined in the study and control groups.

For analysis of the AMLR, the median values and confidence intervals of the measures were compared between the groups (control and study) and intra-group between the right $(\mathrm{RH})$ and left (LH) hemispheres and right (RE) and left (LE) ears of each group.

Confidence intervals were calculated for comparison of the latencies and amplitudes of the AMLR waves. The level of significance for rejection of the null hypothesis was set at $5 \%$.

The analysis was performed with SAS ${ }^{\circledR} 9.0$ software using the PROC MIXED function.

\section{RESULTS}

Each group consisted of 25 children ( 14 boys and 11 girls) with a mean age of 10 years.

Fifteen of the 25 in the study group (60\%) presented with total IQ scores below 80, with 10 between 80 and 85 , 4 between 90 and 100, and 1 scoring 105, this being the highest score obtained; of the remaining 10 children, 2 scored between 80 and 70 and 8 below 70 , with the lowest score being 53 .

The study group yielded significantly lower scores on the assessments of reading and writing; this was especially 
true for reading, with a high frequency of non-responses (62.6\%) due to the non-literacy of most of the children.

Intra-group analysis of the confidence intervals of the AMLR measures showed that only $\mathrm{Na}$ Lat differed significantly at the level of 5\% between the hemispheres, being longer in the right hemisphere than in the left in the control group and the reverse in the study group, in which the Na Lat was longer on the left contralateral pathway (RL $>$ LR, $\mathrm{p}=0.03$ ) (Table 1).

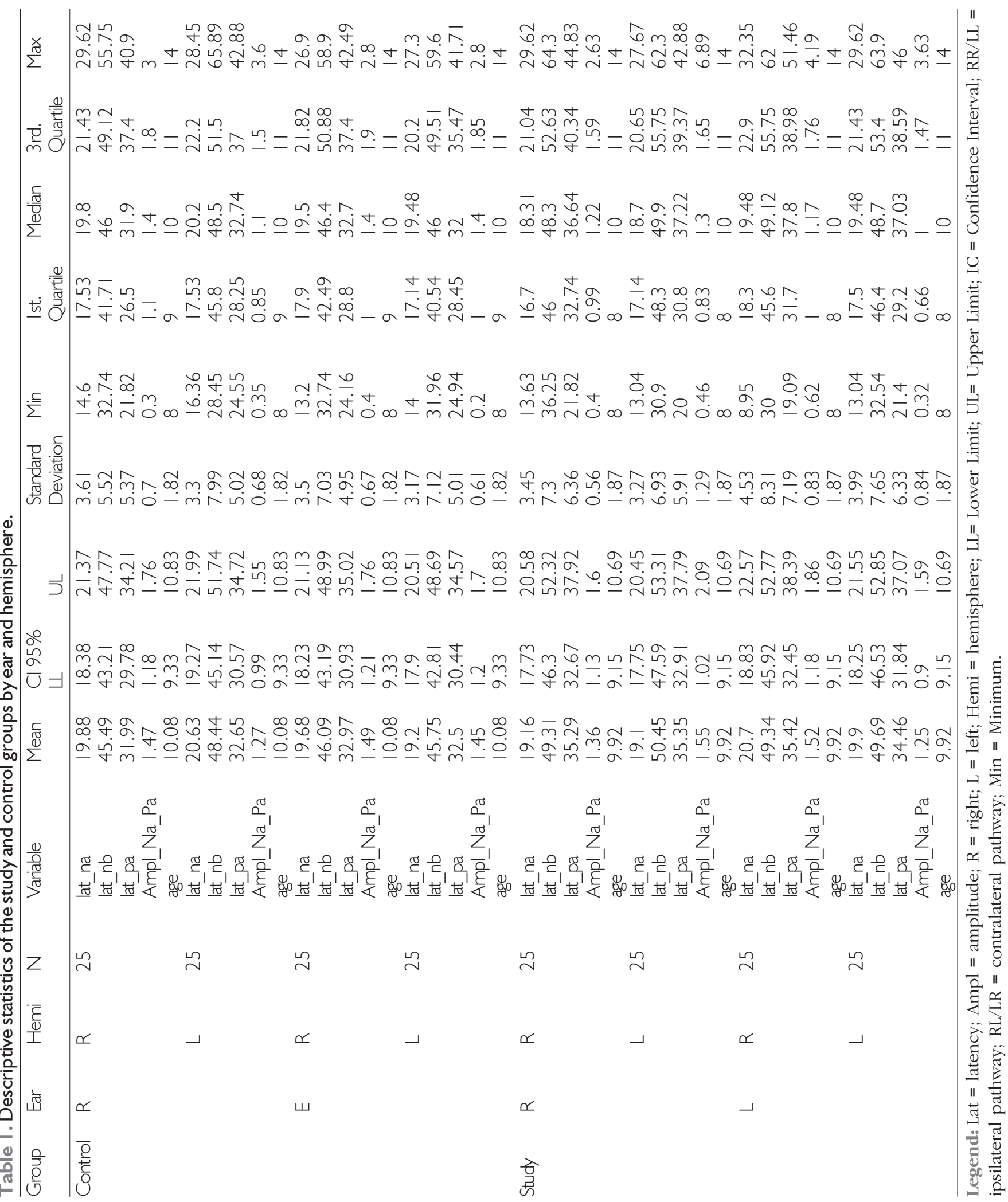


Comparison between the 2 groups showed that the left ear Pa Lat was longer in the study group than in the control group for both the contralateral and ipsilateral pathways. Stimulation of the left ear also produced longer values of $\mathrm{Nb}$ latency in the left hemisphere in the study group than in the right hemisphere in the control group ( $\mathrm{p}$ $=0.02, \mathrm{p}=0.03$ respectively) (Table 2 )

The Na-Pa amplitudes were higher for the left hemisphere contralateral pathway and lower for the left hemisphere ipsilateral pathway in the control group than in the study group ( $p=0.04)$.

\section{DISCUSSION}

This study comprised a representative sample of children who, upon reaching the age of literacy, unexpectedly failed in this first step of success in school learning. Exclusion of children with organic, dysmorphic, genetic, or psychological causes left the sample cases whose predominant difficulty was in reading acquisition. As this study was not intended to focus on dyslexic children, these were the only criteria necessary to produce a representative sample of the patients who present to the clinical practice of a public specialty hospital. Therefore, the assessment of intellectual level served primarily to characterize the sample.
The $\mathrm{Na}, \mathrm{Pa}$, and $\mathrm{Nb}$ components were visualized in the AMLR recordings of all participants with and without learning disabilities, and the average latency of the control group was consistent with the findings of other studies in the international $(3,4,16)$ and Brazilian $(17,18)$ literature.

The different patterns of time response latency observed in the control and study groups were detailed by intra- and inter-group analyses.

In the inter-group comparison, the $\mathrm{Pa}$ latency appeared to be elongated towards the contralateral left in the study group relative to that of the control group.

Most of the significant differences in the intra-group analyses were observed for the wave components $\mathrm{Na}$ and $\mathrm{Nb}$, confirming the sensitivity of these components for identifying functional deficits of the central auditory pathways and the cerebral hemispheres.

Other scholars have previously observed longer latency values for the $\mathrm{Na}$ wave in the left hemisphere in children with learning disorders $(3,4)$.

Poor function of the left main route may have produced difficulties in sound decoding and compromised the association of linguistic components with visual components or even the auditory-linguistic associations at

Table 2. Intra- and inter-group comparisons of ipsi- and contralateral differences with significance values.

\begin{tabular}{|c|c|c|c|c|c|c|c|c|c|c|}
\hline Variable & group & ear & hemi & group & ear & hemi & EstimatedDifference & \multicolumn{2}{|c|}{ UL Cl 95\%LL Cl 95\% } & $\mathrm{P}$ \\
\hline \multicolumn{11}{|l|}{ LatNa } \\
\hline & C & $\mathrm{R}$ & $L$ & C & $L$ & $L$ & 1.42 & 0.001 & 2.85 & 0.04 \\
\hline & $S$ & $R$ & & S & $L$ & & -1.17 & -2.18 & -0.167 & 0.02 \\
\hline & S & $\mathrm{R}$ & $\mathrm{R}$ & S & $\mathrm{L}$ & $\mathrm{R}$ & -1.54 & -2.97 & -0.1232 & 0.03 \\
\hline & $\mathrm{S}$ & $\mathrm{R}$ & $L$ & S & $L$ & $\mathrm{R}$ & -1.60 & -3.02 & -0.18 & 0.03 \\
\hline \multicolumn{11}{|l|}{ Lat_Pa } \\
\hline & C & $\mathrm{R}$ & $R$ & S & $L$ & $\mathrm{R}$ & -3.30 & -6.55 & -0.05 & 0.04 \\
\hline & C & $\mathrm{R}$ & $\mathrm{R}$ & S & $\mathrm{L}$ & $\mathrm{L}$ & -3.36 & -6.61 & -0.10 & 0.04 \\
\hline & C & $\mathrm{R}$ & $\mathrm{L}$ & S & $\mathrm{L}$ & $\mathrm{R}$ & -3.43 & -6.68 & -0.17 & 0.03 \\
\hline \multicolumn{11}{|l|}{ Lat_Nb } \\
\hline & C & $\mathrm{L}$ & & S & $R$ & & -3.96 & -7.58 & -0.33 & 0.03 \\
\hline & C & & $R$ & $S$ & & $\mathrm{~L}$ & -4.28 & -7.90 & -0.66 & 0.02 \\
\hline & C & $R$ & $\mathrm{R}$ & & $R$ & $L$ & -2.04 & -3.89 & -0.20 & 0.03 \\
\hline & C & $R$ & $R$ & $S$ & $\mathrm{~L}$ & $\mathrm{~L}$ & -4.95 & -9.02 & -0.89 & 0.02 \\
\hline & C & $\mathrm{R}$ & $\mathrm{L}$ & $S$ & $L$ & $L$ & -4.20 & -8.27 & -0.13 & 0.04 \\
\hline & C & $\mathrm{L}$ & $\mathrm{R}$ & $S$ & $R$ & $\mathrm{~L}$ & -4.35 & -8.42 & -0.28 & 0.03 \\
\hline & C & $L$ & $\mathrm{~L}$ & $S$ & $\mathrm{R}$ & $L$ & -4.69 & -8.76 & -0.63 & 0.02 \\
\hline \multicolumn{11}{|c|}{ AmplNa-Pa } \\
\hline & C & & $\mathrm{R}$ & $S$ & & $\mathrm{~L}$ & 0.10 & 0.00 & 0.21 & 0.04 \\
\hline & C & $\mathrm{L}$ & $R$ & $S$ & $\mathrm{~L}$ & $\mathrm{~L}$ & 0.15 & 0.00 & 0.30 & 0.04 \\
\hline
\end{tabular}

Legend: $\mathrm{C}$ = control group; $\mathrm{S}=$ study group; Lat = latency; ampl = amplitude; $\mathrm{R}=$ right; $\mathrm{L}=$ left ; Hemi = hemisphere; LL= Lower Limit; UL= Upper Limit; IC = Confidence Interval; RR/LL = ipsilateral pathway; RL/LR = contralateral pathway. 
the level of the primary auditory cortical area in the group with learning disabilities, in which the great majority of children were completely unable to read.

Analysis of the children with learning disorders showed longer latencies for the $\mathrm{Na}$ wave in the left hemisphere $(3,4)$.

Phonological and visual disorders may also be associated and organized into multi-systemic disorders, and the inability of the brain to perform efficient temporal processing of the phonological component significantly impacts reading and writing skills $(19,20)$. A change in temporal processing speed would explain the inability of the children in this study to read and write and would be consistent with the inefficiency of the left hemisphere functions and their integration with the associative paths shown by the inter-group analysis of the results of the study and control groups in this study.

Aside from the discussions of the neurobiological bases and speech pathology manifestations of learning disorders, this study contributes to our knowledge of the particularities of electrophysiological measures, emphasizes that the latencies of waves $\mathrm{Pa}$ and $\mathrm{Nb}$ are longer in the left hemisphere in children with learning disorders, and also demonstrates the diversity of these measures, which could be explained by the heterogeneity of the functional processes of learning.

\section{CONCLUSIONS}

The results from the present sample show that AMLR measures differ between children with (study group) and without (control group) school learning difficulties, especially in reading and writing. The study group exhibited deficits in the left auditory pathway and slower responses in the left hemisphere.

\section{REFERENCES}

1. Richmond M, Robinson C, Sachs-Israel M. (ed) The Global Literacy Challenge. A profile of youth and adult literacy at the mid-point of the United Nations Literacy Decade 20032012. United Nations Educational Scientific and Cultural Organization (UNESCO), 2008.

2. Simos PG, Rezaie R, Fletcher JM, Juranek J, Papanicolaou AC. Neural correlates of sentence reading in children with reading difficulties. Neuroreport, 2011; 22(14):674-8.

3. Purdy SC, Kelly AS, Davies MG. Auditory brainstem response, middle latency response, and late cortical evoked potentials in children with learning disorders. J Am Acad Audiol, 2002; 13(7):367-382.

4. Arehole S, Augustine LE, Simhadri R. Middle latency response in children with learning disbilities: preliminary findings. Journal of Comunications Desorders, 1995; 28:2138.

5. Ozdamar O, Kraus N. Auditory middle latency responses in humans. Audiology, 1983; 22:34-49.

6. Musiek FE, Baran JA, Pinheiro ML. Neuroaudiology: case studies. San Diego: Singular Publishing Group, 1994. 279 p.

7. Borges CF. Processamento temporal auditivo em crianças com transtornos de leitura. [Mestrado] - Faculdade de Medicina da Universidade de São Paulo, São Paulo; 2005.

8. Geisler CD, Frishkopf LS, Rosenblith WA. Extracranial responses to acoustic clicks in man. Science, 1958; 128:121011.

9. Heaton RK, Chelune GJ, Talley JL, Kay GG, Curtiss G. Teste Wisconsin de Classificação de Cartas: manual revisado e ampliado. Adaptação e padronização brasileira. Cunha JÁ, Trentini CM, Argimon IL, Oliveira MS, Werlang BG, Prieb RG. São Paulo: Casa do Psicólogo, 2005.

10. Wechsler D. WISC III: Wechsler intelligence scale for children-manual. 1991. Adaptação e padronização de uma amostra brasileira. Figueiredo, VLM. São Paulo: Casa do Psicólogo. 2002.

11. Tabaquim MLM. Validação do Exame Neuropsicológico e análise das funções corticais superiores em crianças do ensino fundamental. Tese de Pós-Doutorado. Faculdade de Ciências Médicas. Unicamp/Campinas. 2008.

12. Moojen S, Lamprecht R, Santos RM, Freitas GM, Brodacz R, Siqueira M, et al. CONFIAS - Consciência fonológica: instrumento de avaliação sequencial. São Paulo: Casa do Psicólogo. 2003.

13. Capellini AS, Toyota P, Santos LCA, Lourencetti MD, Padula, NAMR. Caracterização do desempenho fonológico, da leitura e da escrita de escolares com dislexia e distúrbio de aprendizagem. Aprender: caderno de filosofia e educação, 2007; 9:37-70.

14. Silver CH, Ruff RM, Iverson G L, Barth JT, Broshek DK, Bush SS, Koffer SP, Reynolds CR. Nan Policy and Planning Commitee. Learning disabilities: The need for neuropsycological evaluation. Arch Clin Neuropsychol, 2008; 23:217-219. 
15. Jasper H. The ten-twenty electrode system of the Internacional Federation. Electroencephalogr Clin Neurophysiol, 1958; 10:371-375.

16. Mcgee T, Kraus N. Auditory development reflected by middle latency response. Ear and Hear, 1996; 17:419-429.

17. Costa SMB, Costa Filho AO, Cardoso MRA. Estudo do potencial auditivo de média latência: efeito de orelha, sexo e idade. Pro-fono R Atual Cient, 2003; 15(2):181-188.

18. Frizzo, ACF, Funayma CAR, Isaac ML, Colafêmina, J.F.
Potenciais evocados auditivos de média latência: estudo em crianças saudáveis. Rev Bras Otorrinol, 2007; 73(3):398403.

19. Habib M. The neurological basis of developmental dyslexia: an overview and working hypothesis. Brain. B, 2000; 123(12):2373-99.

20. Bonifacci P, Snowling MJ. Speed of processing and reading disability: A cross-linguistic investigation of dyslexia and borderline intellectual functioning. Cognition, 2008; 107:9991017. 